\title{
Status Investigation and Construction Strategy of College Students' Safety Culture
}

\author{
Jingya $\mathrm{Li}^{1, \mathrm{a}}$, Dan $\mathrm{Mei}^{1, \mathrm{~b}^{*}}$, Yu Cheng ${ }^{1, \mathrm{c}}$, Wangmei Chen ${ }^{1, \mathrm{~d}}$ and Zheng Cheng ${ }^{1, \mathrm{e}}$ \\ ${ }^{1}$ Hubei Key Laboratory for Efficient Utilization and Agglomeration of Metallurgic Mineral Resources \\ Wuhan University of Science and Technology, Hubei Wuhan 430081, China

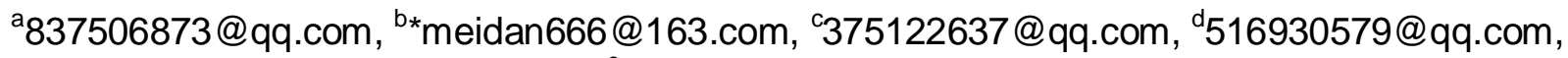 \\ 850998467@qq.com \\ *The corresponding author
}

Keywords: College students; Safety culture; Safety education; Questionnaire; Safety awareness

\begin{abstract}
Due to the frequent safety accidents, the pressure and challenges faced by colleges and universities are growing increasingly. At the same time, higher requirements are put forward to meet the occupational safety needs and strengthen the crisis consciousness on the construction of safety culture. Through the questionnaire surveyed on the students of Wuhan University of Science and Technology, the safety on dormitory and property are taken into consideration so as to study the level of safety awareness and the situation of grasping the safety common sense. The results indicate that: the type of safety education courses is single and safety awareness level exist difference in grade and specialty. So the safety education system should be strengthened and colleges are supposed to increase the variety of safety courses and pay attention to differences in teaching methods.
\end{abstract}

\section{The Significance of College Students' Safety Culture Construction}

Safety culture is put forward by the international nuclear safety advisory group in the report of the Chernobyl accident in the former Soviet Union in the 1980s, which blamed on" the Soviet Union' s nuclear security system existed a major safety culture problem" . Later, safety culture is defined as the sum of the units and individuals existed in all kinds of literacy[1].

For different industries, safety culture has different connotation and characteristics. In colleges and universities, safety culture has the function of orientation, constraint and regulating behaviors[2]. A good atmosphere of security culture can provide a safe environment for teaching, scientific research and learning life both for teachers and students in campus. Due to chaotic social environment and students' weak safety consciousness[3], the pressure and challenges faced by colleges are growing increasingly and accidents from being hurt by others, missing has happened frequently. For example, in 2016, a drunk Hunan female college student was carried to hotel in the case of no consciousness and killed by sex[4]. In 2015, three disappearances of female college students constantly happened in the past ten days in Guangzhou province and one was killed[5].

Besides the security problems for college students at school, the needs for occupational security literacy also sets higher demands upon the construction of safety culture in colleges and universities. College students are the pillars of nation and will serve for all walks of life. Any industry such as construction, chemical, mine, transportation and space has the problems of safety production. Not only do the safety managers need to master the knowledge of safety production, but every employee has its own responsibilities of security as well. Therefore, when learning professional knowledge at the college level, security literacy must be developed and knowledge about safety should be equipped at the same time. For example, DuPont, the world famous company, has taken the construction of safety culture as habituation and institutionalized actions into daily development. Safety is not just the responsibilities of managers, but the responsibilities of every employee. Safe work is the conditions of being hired. All loopholes must be immediately improved and demanding faith and concepts of security have been deep in the hearts of staff, which realizes the leap from employees' passive obedience to help each other, share the safety knowledge and experience as 
teams in the development of enterprise safety culture. Nowadays, the safety performance of DuPont has hit a double ten times, that is, a better safety record than that of other enterprises and more secure for employees during work than after work[6]. The achievements benefit not to the cultivation that DuPont has made for every employee, but to the good atmosphere of security culture and the implementation of safety management system.

Relative to the security problems of study and work, the crisis consciousness in the face of disasters should not be ignored as well. Flood, earthquake and other natural disasters has taken place frequently. Therefore, people must have the ability to save themselves and help others in disasters and self protection such as self-rescue, basic knowledge of first aid[7] in the complicated social environment are all the basic requirements of survival. Setting up the concept of survival, developing the survival education and improving the crisis awareness is the inevitable choice for colleges to meet the requirements of society[8].

In order to know the level of college students' security awareness and the master of basic common sense about security, discovering the blind spot of safety culture at colleges[9], creating a good campus environment, maintaining the security and stability of the colleges, a study on the present educational situation and college students' awareness of safety culture is made in Wuhan University of Science and Technology.

\section{Current Situation of College Students' Safety Education}

Through the study of total 17 universities including Shanghai Jiao Tong University, Fudan University, Shanghai University, Shanghai Theater Academy, Wuhan University, Huazhong University of Science and Technology, Wuhan University of Technology, Hubei University, Sun Yat-Sen University, Jiangsu University, Nankai University, Yangzhou University and Yunnan University, Northeast Normal University, Jilin University, Shandong University, Chongqing University, the realization of safety education being brought into the classroom accounts less than 60percent, being written into the textbook less than 40percent and only 10 percent related to credits. At present, a large number of universities such as Peking University, Shanxi University, Tianjin University, Hainan University have offered selective courses on safety education. However, few education departments or colleges take the safety education courses as a profession or making a system planning of it. Hardly can see the safety education establish as a compulsory course for college students, especially being written into the talents cultivation plan. Safety education still has no unified curriculum design [10].

Besides the safety engineering students, according to the survey, public elective courses and experiment courses are the main form for safety education in Wuhan University of Science and Technology. Public elective courses involving food safety and public rescue, 40 class hours for per course. One class hour are separated out for laboratory safety learning on lab experiments. Safety education has not yet been included in the compulsory course, the types only involving food safety, rescue and laboratory safety, which are few.

\section{Respondents and Investigation}

Surveyed on the students of Wuhan University of Science and Technology, through random sampling, 150 questionnaires were sent out to students from 7 faculties and 4 grades and 150 questionnaires were collected. The recovery rate is 100 percent. The effective rate is 100 percent. According to the significant differences of survey data, there are three classifications:

According to majors (There are 83 questionnaires accounting for 55.33 percent from the students majoring in safety science and engineering discipline and 67 questionnaires accounts for 44.67 percent from other majors.);

According to grades (There are 37 students from lower grades accounting for 24.67 percent and 113 students from higher grades accounts for 75.33 percent).

Through the questionnaire surveyed, safety of dormitory, personal and property are taken into consideration so as to study college students' safety awareness. 
The investigation is shown in Table 1. It mainly consists of three parts:

Personal information: including gender, faculties, grades and majors;

The cognition of security issues: particularly studying on the aspects of the awareness of fire safety in dormitory and property safety;

The proficiency in handling safety accidents: including the mastery of using fire hydrants, the prevention and treatment of accidents, the treatment to unlawful infringements.

Table 1 The main content of the questionnaire

\begin{tabular}{|c|c|}
\hline Contents & Problems \\
\hline \multirow{3}{*}{$\begin{array}{l}\quad \text { Part A: } \\
\text { Personal } \\
\text { information }\end{array}$} & A1: What faculties are you in? \\
\hline & A2: What grades are you in? \\
\hline & A3: Do you major in safety science and engineering discipline? \\
\hline $\begin{array}{c}\text { Part B: } \\
\text { The } \\
\text { cognition of } \\
\text { security } \\
\text { issues }\end{array}$ & B1: Have you ever used high-power electrical appliances in dormitory? \\
\hline \multirow{4}{*}{$\begin{array}{c}\text { Part C: } \\
\text { The } \\
\text { proficiency } \\
\text { in handling } \\
\text { safety } \\
\text { accidents }\end{array}$} & C1: Do you know how to use fire hydrants in the right way? \\
\hline & $\begin{array}{l}\text { C3: Do you know the self protection measures when stampede accidents } \\
\text { happens? }\end{array}$ \\
\hline & C4: Do you know how to do when earthquake happens? \\
\hline & $\begin{array}{c}\text { C5: Do you know the relative points for attention when elevator accidents } \\
\text { happens? }\end{array}$ \\
\hline
\end{tabular}

\section{Situation Analysis}

Fire Safety Awareness in Dormitory. Dormitory is the place where students gathered. Have a good awareness of dormitory, mastery the methods of the identification of dangerous and hazardous factors. Only in this way can the unsafe state be decreased to the minimum. Through the survey (Table 2), when it comes to the series of fire safety problems, 53.56 percent of students said they once used high-power electrical appliances in dormitories, which accounts over half. Only 16.21 percent of lower grade students have never used them while the percentage accounting for 30.23 in higher grade students. Obviously, there exists difference in grades on the level of safety awareness. Above all, relative to the lower grade students, students with higher grades have a greater awareness of fire safety. Safety awareness increases with the grade of students.

Table 2 Situation of safety awareness in college students of different grades

\begin{tabular}{|c|c|c|}
\hline \multirow{2}{*}{ Percentage } & \multicolumn{2}{|c|}{ Whether using high-power electrical appliances in dormitory } \\
\cline { 2 - 3 } & Yes & No \\
\hline Lower grade students & $33.79 \%$ & $16.21 \%$ \\
\hline Higher grade students & $19.47 \%$ & $30.23 \%$ \\
\hline Total & $53.56 \%$ & $46.44 \%$ \\
\hline
\end{tabular}

Due to the use of high-power electrical appliances in dormitory, lines aging and plug leak, the fire problem has become an important aspects of security problems on campus. Based on security, colleges overhaul fire equipment regularly and do fire fighting exercise each term in the hope that it works out in emergency. However (Table 3), only 13. 25 percent of students who majoring in safety science and engineering discipline and 5.97 percent of students in other majors gain proficiency in 
how to use fire hydrants. Up to 46.27 percent of students in other majors know little about it and 28.36 percent of them even know nothing about it. There exists a great difference in the proficiency in using fire hydrants in different majors. The students majoring in safety science and engineering discipline do better than others No systematic learned the use of fire equipment and low rate of fire drills lead to the low acceptance among students. Therefore, the level of fire skills remains to be improved.

Table 3 The proficiency in using fire hydrants in different majors

\begin{tabular}{|c|c|c|c|c|c|}
\hline Percentage & $\begin{array}{c}\text { Know it pretty } \\
\text { well }\end{array}$ & $\begin{array}{c}\text { Have a general } \\
\text { understanding }\end{array}$ & $\begin{array}{c}\text { Know } \\
\text { little }\end{array}$ & Know nothing & Total \\
\hline $\begin{array}{c}\text { science } \\
\text { and } \\
\text { engineerin } \\
\text { g } \\
\text { discipline } \\
\text { students }\end{array}$ & $13.25 \%$ & $44.59 \%$ & $34.94 \%$ & $7.23 \%$ & $100.00 \%$ \\
\hline $\begin{array}{c}\text { Other } \\
\text { major } \\
\text { students }\end{array}$ & $5.97 \%$ & $19.40 \%$ & $46.27 \%$ & $28.36 \%$ & $100.00 \%$ \\
\hline
\end{tabular}

\section{Personal Safety Awareness}

There are lots of assemblies in university. Because of college students' curiosity, getting involved, impulsion and conformity, stampede accidents are more likely to happen, which may cause casualties and bring about a bad effect on society. The survey (Fig 1.) show that 30 percent of students don' t know what to do when stampede accidents happen. There is a great possibility that they will become victims if stampede accidents happen. 30 percent of students have a general understanding about it. Fears and panics might disturb thoughts when stampede accidents really happen and the only existent knowledge in mind will be forgotten because of it. Therefore, the percentage rate of students who can take effective measures will decline under the actual situation.

Elevator accidents have also happened frequently on news report recently. College students should have a clear understanding of the accidents. However (Fig 1.), more than half of the students only have a general mastery of the safety measures. They need time to recall and judge what to do in real situation. 25.33 percent of students are proficiency in the protective measures of elevator accidents and take with calm in emergency.

The probability of occurring a natural disaster is smaller than stampede accidents and elevator accidents. But it will have extremely serious consequences if it happens and casualties can not be avoided, too. measures. For example, Wenchuan Earthquake in 2008, in Anxian county of Mianyang city, a middle school with more than 90 teachers and 2200 students only took 1 minute and 36 seconds to the playground and had no casualties because of usual experiences about earthquake. Through the survey on the safety measures of earthquake (Fig. 1.), college students know little about the skills of natural disasters. 20.00 percent of them even know nothing about it and only 5.33 percent of them master the knowledge pretty well. 


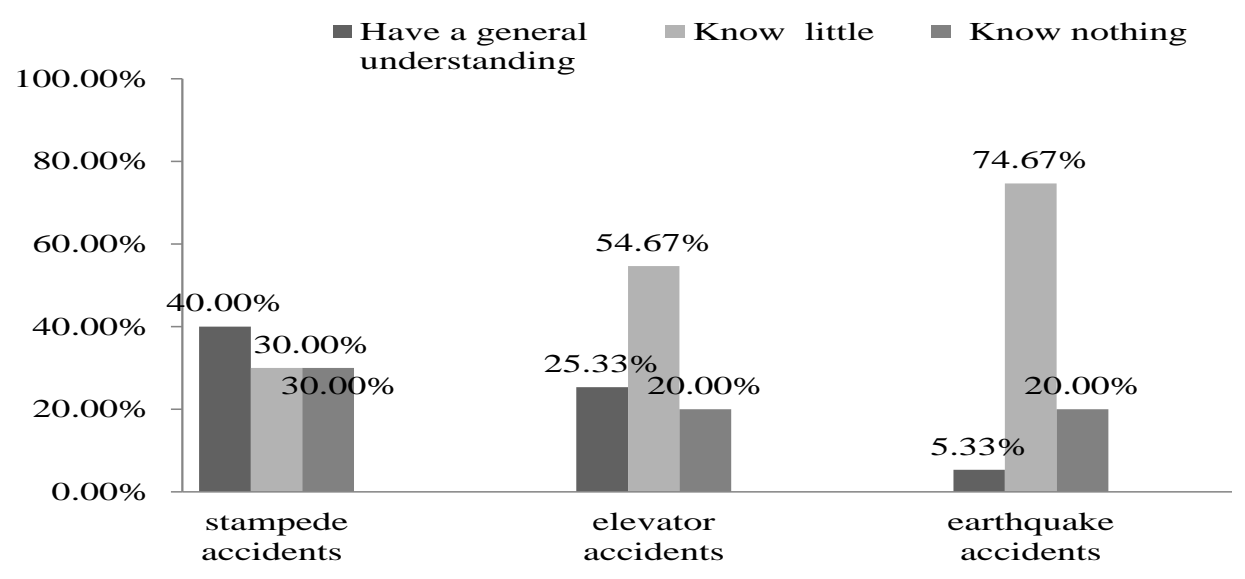

Figure 1. Situation of how to self-help when the accident happened

Accidents may happen in our life so it' s necessary to mater some simple first-aid knowledge such as bandaging, emetic methods, artificial respiration, etc. (Table 4) However, only 5.33 percent of students know it pretty well. Nearly one-third of students said they know nothing about first aid knowledge. 35.33 percent of them know little. First-aid courses are not included in basic courses in China. College students' first-aid skills have a great part of the room for improvement.

Table 4 Mastery of first aid knowledge

\begin{tabular}{|c|c|c|c|c|c|}
\hline Percentage & $\begin{array}{c}\text { Know it } \\
\text { pretty } \\
\text { well }\end{array}$ & $\begin{array}{c}\text { Have a general } \\
\text { understanding }\end{array}$ & Know little & $\begin{array}{c}\text { Know } \\
\text { nothing }\end{array}$ & Total \\
\hline percent & $5.33 \%$ & $26.67 \%$ & $35.33 \%$ & $32.67 \%$ & $100.00 \%$ \\
\hline
\end{tabular}

\section{Strategies for the Construction of College Students' Safety Culture}

Strengthen Safety Education System. Safety education has not get the attention deserved in our country. To solve this problem fundamentally, the mechanism of safety education should be strengthened and the system of safety culture education is ought to be enriched. For example:

Each colleges and universities must establish specialized courses about safety education every semester[11]. The protection and self-rescue about security issues such as personnel, property, fire hazards, nature disasters, elevator accidents, transportation must be taught on class. Corresponding simulation practice arrangements should be included in the courses so as to help students apply them[12]. The class hours should no fewer than 16, the credits no fewer than 2 , meanwhile, colleges students have to pass exams per term;

At least a fire drill and an earthquake evacuation drill should be held each term;

Safety knowledge contests ought to be held at least once a year and the competition should contain the personnel safety, transportation safety, fire escaping, nature disasters, property safety, emergency medical aids and other safety issues.

Increase the Variety of Safety Education Courses. Few types of safety education courses has been a nagging question. The key lies in how to enrich the courses of safety education. Apart from traditional courses such as laboratory safety, fire safety, food safety and nature disasters, the scope of first aid class are supposed to be expanded. The concentration should not be set only on safety problems resulting from social environment, the electricity safety at home, even the safety of using kitchen wares can be brought into the field of safety education. The courses do not need to be taught in classrooms like other general education curriculum. They can be performed as scenario simulation exercises, drama performances about safety problems on autonomous class or have the courses attached to the Internet[13]. It can be called as safety education courses as long as students 
can gain safety knowledge from it. In addition, safety education has developed more mature in the west and excellent courses can be learned from each other[14][15].

Pay Attention to Differences and Teach Students in Accordance of Their Characteristics. For the diverse safety awareness of different groups, various courses should be taught in classes. For instance:

Students with higher grades have a greater awareness of fire safety. Therefore, more attention should be paid on the education of lower grade students while more concentration on the training of emergency medical aids for higher grade students;

Students majoring in safety science and engineering discipline learn more about how to use the fire hydrants. Therefore, training about using fire equipment ought to be taught in other majors to narrow the gap between the students in diverse majors on the daily operation of safety facilities.

\section{Acknowledgements}

This paper is supported by Hubei Province Education Department of education teaching and research project (project number 2015230), Hubei Province College Students' innovative research project (project number 201610488034), Wuhan University of science and technology teaching and research project (project number YJG 201529) and Hubei Province Natural Science Foundation of China. (project number 2016CFC750)

\section{References}

[1] Information on http://baike.so.com/doc/4337962-4542845. html

[2] C. C. Zou, Huxiang Forum, Vol. 18 (2005) No. 2, p. 87-88. (In Chinese)

[3] L. X. Deng, Contemporary Educational Science, Vol. (2015) No. 14. (In Chinese)

[4] Information on http://news.qq.com/a/20160909/044103. html

[5] Information on http://news.163.com/15/0923/02/B45R2N2400014Q4P_2.html

[6] S. C. Tian and G. X. Jing: Safety Management (China Machine Press, China 2009).

[7] J. G Zhang: The Status and Countermeasure Research of the First-Aid Training in the College Students(Ma. D, School of Medicine of Zhejiang University, China 2008). (In Chinese)

[8] X. Che. Science Tribune, Vol. (2016) No. 1, p. 30-32. (In Chinese)

[9] H. Shao and K. Q. Wang, Journal of Changzhou University (Social Science Edition), Vol. 5(2004) No. 2, p. 45-47. (In Chinese)

[10] Y. Yang and F. Zheng, Journal of Leshan Teachers College, Vol.(2014) No. 4. (In Chinese)

[11]D. Li and Y. Cheng, Theory and Practice of Contemporary Education, Vol. 6 (2014) No. 2, p. 72-73. (In Chinese)

[12] Y. Yao, Education Science, Vol. 24 (2008) No. 4, p. 62-65. (In Chinese)

[13] H. Y. Zheng, W. Wang and Y. Liu, Journal of Chongqing University(Social Science Edition), Vol. 22 (2016) No. 4, p. 212-218. (In Chinese)

[14] W. Xia, B. Wang, L. Liu and Y. P. Wang, Hubei Sports Science, Vol. 30 (2011) No. 5, p. 502-504. (In Chinese)

[15] M. Wang and J. Shi, Journal of Tonghua Normal University, Vol. 3 (2012) No. 3, p. 89-91. (In Chinese) 